\title{
HVMANITAS
}

\section{Retórica e historiografia: a arenga militar do século XVI}

Autor(es): Henriques, Luís Miguel

Publicado por: Imprensa da Universidade de Coimbra

URL

persistente:

URl:http://hdl.handle.net/10316.2/35109

DOI:

DOI:http://dx.doi.org/10.14195/2183-1718_66_18

Accessed : $\quad$ 26-Apr-2023 02:22:35

A navegação consulta e descarregamento dos títulos inseridos nas Bibliotecas Digitais UC Digitalis, UC Pombalina e UC Impactum, pressupõem a aceitação plena e sem reservas dos Termos e Condições de Uso destas Bibliotecas Digitais, disponíveis em https://digitalis.uc.pt/pt-pt/termos.

Conforme exposto nos referidos Termos e Condições de Uso, o descarregamento de títulos de acesso restrito requer uma licença válida de autorização devendo o utilizador aceder ao(s) documento(s) a partir de um endereço de IP da instituição detentora da supramencionada licença.

Ao utilizador é apenas permitido o descarregamento para uso pessoal, pelo que o emprego do(s) título(s) descarregado(s) para outro fim, designadamente comercial, carece de autorização do respetivo autor ou editor da obra.

Na medida em que todas as obras da UC Digitalis se encontram protegidas pelo Código do Direito de Autor e Direitos Conexos e demais legislação aplicável, toda a cópia, parcial ou total, deste documento, nos casos em que é legalmente admitida, deverá conter ou fazer-se acompanhar por este aviso. 
humanitas

Vol. LXVI

2014

IMPRENSA DA UNIVERSIDADE DE COIMBRA

COIMBRA UNIVERSITY PRESS 
RETÓRICA E HISTORIOGRAFIA: A ARENGA MILITAR DO SÉCULO XVI

RHETORIC AND HISTORIOGRAPHY: THE MILITARY HARANGUE OF THE SIXTEENTH CENTURY

\author{
Luís Miguel Henriques \\ Instituto Politécnico de Portalegre \\ luduvicus.m@gmail.com
}

\begin{abstract}
Resumo
Atendendo à tradição retórico-literária que vinha da Antiguidade, os historiadores portugueses do século XVI introduziram nas suas obras numerosas arengas militares, a fim de caracterizarem os seus protagonistas e emocionarem os seus leitores. Este artigo analisa, a partir de diferentes perspetivas e transversalmente, o papel da arenga militar na historiografia e na épica portuguesas do século XVI, focando, em especial, os tópicos retóricos mais destacados da respetiva argumentação.

Palavras-chave: retórica, historiografia, arenga militar, século XVI.

Abstract

Given the rhetorical-literary tradition that came from antiquity, the Portuguese historians of the sixteenth century introduced in their works numerous military harangues, in order to characterize their protagonists and impress their readers. This article analyses, from different perspectives, the role of the military harangue in historiography and Portuguese sixteenth century epic, focusing, in particular, on the rhetorical topics of the respective arguments.
\end{abstract}

Keywords: rhetoric, historiography, military harangue, sixteenth century. 


\section{A arenga militar na historiografia antiga}

Este artigo tem a finalidade de analisar, sob diferentes perspetivas e de forma condensada, o modo como a épica e sobretudo a historiografia quinhentistas integraram e modelaram um tipo de discurso - a arenga militar - que contava já com uma larga tradição histórico-retórica, cujas origens remontam à Antiga Grécia, nomeadamente a autores como Homero e Tucídides, verdadeiros precursores na arte de inserir discursos nas respetivas narrações.

Por um processo de influência literária grega, a arenga militar acabou por se converter numa componente essencial tanto da historiografia e épica romanas, ${ }^{1}$ como da historiografia bizantina e medieval, ${ }^{2}$ procedendo cada uma delas às devidas adaptações formais e ideológicas. De igual modo, no século XVI, época em que a Europa acolhia com entusiasmo os influxos culturais da Antiguidade Clássica, também os historiadores portugueses do Renascimento integraram nas suas obras os valores e a tradição retórico-literária subjacentes, a fim de exaltarem os heróis e a gesta ultramarina.

1.1. Definição. A arenga militar é um discurso de dimensão variável, proferido por um general (antes, durante ou depois de uma batalha ou campanha militar), formalmente em discurso direto (oratio recta) ou indireto (oratio obliqua), de temática guerreira, cujo objetivo é provocar uma reação emocional nos militares. Para esse efeito, o orador recorre a uma série de argumentos ou topoi retóricos, a maioria dos quais com uma sólida tradição retórico-literária, procurando, assim, afastar o temor da mente dos soldados e infundir-lhes a confiança necessária na vitória.

1.2. Conceção da obra histórica na Antiguidade. Tanto na Antiguidade Clássica como no Renascimento, a obra histórica era percecionada não só como um instrumento de preservação da memória, mas também como uma composição literária e erudita, em que a tradição e a imitação desempenham um papel importante. ${ }^{3}$ Só assim se compreenderá a inserção da arenga na obra histórica, de forma que é necessário compreendê-la mais como um produto literário vinculado a uma tradição retórica, do que como um elemento

1 Vide Harto Trujillo (2008) sobre o papel das arengas militares na historiografia latina.

2 Vide Blise (1989; 1991 e 1994), Chaparro Gómez (2008) e Garcia Fitz (2008) sobre a importância da exortação militar na Idade Média.

3 Cf. Iglesias Zoido 2008: 20. 
histórico. Com a obra histórica, o historiador clássico procurava ensinar (docere), entreter (delectare) mas também comover (mouere) o leitor, por isso em autores como Tito Lívio ou Políbio e por imitação em historiadores portugueses de Quinhentos vigorava uma conceção dramática da história que visava impressionar o mesmo leitor, daí que pelas suas páginas perpassem numerosas cenas de batalhas, cercos de cidades, parlamentos e sobretudo discursos ${ }^{4}$ como a arenga militar.

1.3. Estado da Questão. Foi sobretudo a partir do século XX e com maior profusão nas últimas três décadas que os investigadores passaram a interessar-se em analisar as relações entre retórica e historiografia, centrando-se num vasto período que vai da Antiguidade até ao Renascimento. A partir da segunda metade do século XX, emergiu uma visão da historiografia que já não entende que a criatividade dos historiadores antigos estivesse submetida aos rigores da procura da verdade de ações e feitos, mas sim que a mesma historiografia antiga deve ser apreendida como um género literário concreto, com tudo o que isso implica. Assim, tanto ações como discursos devem ser interpretados mais como produtos literários do que como simples representações históricas.

1.4. Tradição. O primeiro modelo influente de arengas da literatura grega é o modelo homérico. Homero inseriu um número considerável de arengas na Ilíada, proferidas, na sua larga maioria, no decurso de batalhas. Tal circunstância implica que se trate de breves discursos diretos, cuja extensão não vai além de seis versos, preenchidos com tópicos universais de incentivo ao combate, como o apelo ao comportamento valente e a censura à conduta ignominiosa. Resulta daqui que a exiguidade de tais arengas coarte a sua profundidade argumentativa.

Do ponto de vista historiográfico, o modelo homérico acabou por ser integrado primeiramente por Heródoto nas suas Histórias. Trata-se de um discurso designado pelo próprio historiador como parainesis, discurso composto por tópicos simples e diretos que se aproximam daquilo que o general realmente poderia pronunciar num momento crucial de uma batalha, como seria o seu início.

Deve-se, porém, a Tucídides a proposta de um modelo criativo de arenga distinto do anterior modelo homérico, que acabará por se tornar

4 Cf. Navarro Antolín 2000: 81.

Humanitas 66 (2014) 349-365 
fundamental no desenvolvimento do género historiográfico. Hansen ${ }^{5}$ considera que Tucídides foi o inventor da arenga historiográfica, fonte de inspiração mais importante para as gerações seguintes de historiadores, gregos, romanos e renascentistas.

Com Tucídides, a arenga sofre um processo de reelaboração criativa e compositiva, passando a ter uma estrutura mais ampla e complexa, integrando-se perfeitamente na narrativa dos feitos históricos. Este inovador modelo de arenga historiográfica amplificava as breves exortações não só constantes do modelo literário de Homero, como as que verdadeiramente poderiam ser pronunciadas pelo general no campo de batalha. De facto, as condições materiais do campo de batalha inviabilizariam a pronunciação de discursos extensos e complexos, pelo que, em consequência disso, Hansen não tem dúvidas de que o modelo tucidideano de arengas era uma invenção literária, cujo universo de realização é exclusivo da historiografia.

$\mathrm{Na}$ base desta inovação discursiva, ${ }^{6}$ está a maneira como Tucídides interpretou a função dos discursos na história, elevando e colocando-os ao mesmo nível da narração dos feitos históricos. Isso mesmo afirma o historiador grego, no amplamente debatido capítulo metodológico (1.22) da sua obra:

No que concerne aos discursos constantes nesta história, alguns foram proferidos antes da eclosão das hostilidades, outros já durante o seu decurso. Alguns deles ouvi-os eu pessoalmente, doutros tomei conhecimento através de diversas fontes. Em qualquer dos casos, foi difícil conservá-los, palavra por palavra, na memória de alguém. Por isso, adoptei o método de fazer os oradores dizer aquilo que me pareceu ser o que lhes era exigido por cada uma das circunstâncias, obviamente procurando reflectir o mais possível, o sentido geral daquilo que realmente afirmaram. ${ }^{7}$

Como se comprova pela leitura deste excerto, os discursos e a narrativa dos acontecimentos surgem no mesmo patamar de igualdade. A partir deste programa metodológico, Tucídides afasta-se dos seus antecessores, de tal maneira que as suas arengas já não se subordinam à narração mas "atuam" conjuntamente. Neste sentido, é lícito afirmar-se que Tucídides criou uma tipologia dúctil de arengas, capaz de se adaptar a diferentes contextos

5 Cf. Hansen 1993: 161-180.

6 Cf. Iglesias Zoido 2008a: 240-258.

7 Thu.1.22. 
narrativos. Com este modelo de arengas, o historiador tem por objetivo não só aproximar o mais possível o discurso àquilo que fora pronunciado pelo general, como pretende sobretudo estabelecer uma dinâmica com a narrativa dos feitos, antecipando uma tática militar que de imediato se porá em prática, mostrar a argúcia de um general, ou ainda tornar mais transparentes os verdadeiros motivos que estiveram por detrás de uma vitória ou de uma derrota.

Para a criação desta arenga flexível e adaptável a distintos contextos narrativos, Tucídides valeu-se da retórica e da oratória de finais do século $\mathrm{V}$ a.C., concertando aquelas potencialidades que lhe pareciam mais profícuas. Assim, o seu modelo de arenga resulta daquele reduzido número de tópicos que um general poderia pronunciar diante do seu exército, amplificado com o recurso ao conteúdo argumentativo dos três géneros retóricos (deliberativo, judicial e epidítico) apontados pela retórica aristotélica. Ainda que fosse comum à retórica sofística combinar num mesmo discurso linhas argumentativas de discursos distintos, nunca havia sido enunciada a possibilidade de concertação dos três géneros retóricos. Assim, a nova parainesis proposta por Tucídides resulta da convergência de duas linhas argumentativas de origens distintas: uma de tipo explicativo (didache) proveniente da oratória deliberativa, cujo objectivo é mostrar às tropas que o cenário militar que irão enfrentar lhes é favorável e promissor, ao mesmo tempo que é traçada a estratégia a executar para vencer o inimigo, evocando-se exemplos passados que podem ser vantajosos para o momento presente; a outra, a parakeleusis, de pendor exortativo, inspirada no modelo homérico de arenga e na secção protréptica do discurso fúnebre, procura galvanizar as tropas para o combate, sustentando a argumentação na necessidade de se honrar o valor dos antepassados ou de que se deve preferir uma morte honrosa. Por sua vez, cada uma das componentes argumentativas da arenga desenvolverá uma série de topoi ou lugares-comuns argumentativos, denominados pelos rétores da historiografia greco-latina como telika kefalaia ou capitula finalia. Assim, podem ser identificados quatro grandes núcleos argumentativos: o general que pretende exortar as suas tropas para a batalha há-de demonstrar que a mesma é justa (dikaion), é útil (sumpheron) pois defende o Estado e o indivíduo e evita consequências, é ainda possível (dunaton) e honroso (endoxon). A estes quatro, juntar-se um quinto tópico constante da historiografia, ou seja, as consequências negativas de uma derrota (ekbesomenon).

Na maioria dos casos, uma arenga é pronunciada pelo chefe militar quando este se apercebe de que o temor e o desânimo grassam no seio do 
exército e é necessário infundir novamente ânimo e restaurar a confiança na vitória. Ora, a componente explicativa, didache, tem exactamente esta designação porque lhe tem associada a ideia de "instruir" ou de "recordar". Na verdade, o chefe militar instruirá as suas tropas expondo-lhes a estratégia que se porá em prática, aproveitando para trazer à memória feitos ilustres dos antepassados. Esta componente não é só percetiva, mas sobretudo emotiva, pois, a exposição da estratégia há de ser de tal maneira motivadora que as tropas se galvanizarão para o combate, crendo na vitória, desapossando do ânimo a desconfiança e o temor. É o momento oportuno para o líder militar assentar a sua estratégia argumentativa nos tópicos de que a vitória está ao alcance, hiperbolizando alguma vantagem militar própria, ao mesmo tempo que identifica um ponto fraco no inimigo. Deve trazer-lhes à memória uma vitória, deles ou dos seus antepassados, contra os mesmos inimigos, demonstrando-lhes que a ação que se prepararam para realizar é justa, porque apenas respondem a um agravo cometido pelos inimigos, tendo, por isso, o favor dos deuses. Vincará ainda que a vitória é útil para a defesa da pátria e da liberdade individual. Pelo exposto, a componente instrutiva da arenga é o elemento nuclear de muitas arengas, quer em Tucídides, quer na historiografia portuguesa de Quinhentos.

Foi assim que Tucídides, de uma tradição em que a arenga era composta por breves exortações, criou um discurso dinâmico que combina distintos tópicos argumentativos relacionados com o contexto narrativo envolvente e também com os objetivos do historiador. Este novo modelo de discurso parenético apoiado nos capitula finalia e com uma capacidade de se adaptar a novos contextos narrativos, tornou-se rapidamente em modelo de referência para a oratória militar dos vindouros historiadores, como Políbio ou Salústio, bem como a historiografia renascentista.

\section{A arenga militar na historiografia quinhentista}

O primeiro passo para o estudo da arenga militar quinhentista foi dado com a elaboração de um corpus discursivo reunido a partir das obras escritas no século XVI. Esse corpus excede largamente as duas centenas de arengas, selecionadas em géneros literários tão distintos como a historiografia, a épica e até a poesia novilatina. A arenga militar encontra também acolhimento na tratadística militar publicada em Portugal, particularmente na Arte da Guerra do Mar (1555) de Fernando Oliveira, assim como no manual de Doctrina Militar (1598) do italiano Bartolomeu Scarion de Pavia. 
Aquela elevada cifra de discursos militares só se compreende à luz do progressivo número de obras escritas e impressas que, desde meados do século, vinham divulgando em vernáculo e em latim, a gesta dos Portugueses alcançada nos diferentes palcos por onde exerciam a sua influência. É pois dessa matéria-prima de fastos históricos que os autores edificaram as suas obras, que, tocadas por renovados ventos de retórica, aspiravam a ser não só secos repositórios da gesta lusíada, como também composições literárias e eruditas, capazes de seduzirem e comoverem os seus leitores. Com este intuito, construíram carateres vivos dos protagonistas militares portugueses, colocando-lhes na boca discursos vários, designadamente arengas militares, imersas em dramáticas descrições de batalhas. Por essa razão, a arenga militar é o discurso mais característico da historiografia e da épica portuguesas do século XVI.

2.1. Oradores e superfície. A tratadística militar, de Onassandro a Scarion, preconiza que, por dever de ofício, cumpre ao $d u x$, ao general, exortar as tropas em momentos de desânimo. Em certa medida, a historiografia portuguesa está em linha com a tradição prévia, pois são os capitães que mais exercem este ministério oratório. Pelo número de alocuções proferidos, destacam-se, neste aspecto, os heróis dos cercos de Diu (1538 e 1546), António da Silveira, D. João de Mascarenhas e D. João de Castro. Em situações pontuais, porém, nomeadamente durante as batalhas, um soldado mais audaz pode quebrar a tradição e assumir-se como orador de ocasião, a fim de resgatar os companheiros do desânimo.

A este previsível grupo de oradores junta-se um outro inusitado. As mulheres de Diu, heroínas da resistência àqueles dois assédios, o exército das matronas, ${ }^{8}$ desempenharam um papel exortativo e guerreiro na defesa daquela praça, atitude que em nada fica atrás das célebres Amazonas da Antiguidade. A este grupo soma-se ainda um surpreendente conjunto de religiosos que em momentos de angústia arvoram a cruz de Cristo como tónico anímico junto dos que desanimam, a que acrescentam curtos, mas incisivos apelos à luta contra os inimigos da fé.

Se a maioria é proferida em superfície terrestre, com o orador apeado ou montado a cavalo, os dados mostram também que cerca de $1 / 4$ das arengas são pronunciadas a bordo de um vaso de guerra. Tal facto demonstra a importância que a defesa do mar tinha para a manutenção do imperium

8 Couto, Ásia, 6.2.4. 
português. A relevância do mar é tal que até se conta, entre os discursos, um pequeno número de epipolesis proferidas a bordo de uma pequena fusta, o que demonstra a receção de um tópico já presente na literatura clássica, mormente em Lucano (4. 475-521), quando Volteyo, a bordo de uma balsa, empreende também uma epipolesis naval noturna.

2.2. Tipologia. A receção pelos historiadores portugueses do modelo flexível proposto por Tucídides permitiu a constituição de uma tipologia de arengas elaborada segundo o critério da produção da alocução, antes, durante ou após uma batalha, sem descurar o tipo de recetor da mesma. Neste sentido, foi possível construir uma tipologia que conta com seis tipos discursivos:

T1 - arenga proferida aos comandos intermédios antes de um combate;

$\mathrm{T} 2$ - arenga proferida diante de uma assembleia de tropas antes de um combate;

T3 - arenga proferida diante de tropas em formação nos momentos prévios ao combate;

T4 - revista de tropas (epipolesis);

T5 - arenga proferida durante um combate;

T6 - arenga proferida depois de um combate.

Os resultados mostram que são as arengas T2 e T5 as que encontram maior expressão e acolhimento por parte dos historiadores. As alocuções T2 são as mais extensas, as mais elaboradas e as que reúnem o maior número de topoi retóricos e respetivo desenvolvimento. São estas a essência da arenga historiográfica; nelas o historiador deixa esculpidos os conhecimentos compositivos de um discurso e o manejo da retórica e da tradição historiográfica prévia. Já as T5 propiciam o dramatismo inerente ao desenrolar de um combate, sendo igualmente o tipo discursivo que permite a introdução de outras variáveis, como a participação das mulheres e dos frades enquanto emissores de arengas. De notar ainda que a historiografia portuguesa não foi alheia a um tipo de discurso cuja origem remonta à épica homérica, a epipolesis (T4). Trata-se de um tipo particular de alocução que é pronunciada pelo capitão enquanto passa revista às tropas. A epipolesis contribui para a atribuição do estatuto de herói do seu emissor, já que a sua representação remete para desempenho dos heróis da Ilíada, como Agamémnon e Heitor, cumprindo a dupla função de generais e de soldados. 
2.3. Argumentatio. Ao longo deste ponto procederemos a uma breve análise dos topoi retóricos (os telika kefalaia ou capitula finalia) mais importantes que cada uma das linhas argumentativas, a didático-instrutiva e a exortativa, desenvolve. Recordemos, entretanto, que, com este termo "atestigado a partir da época imperial, los rétores aluden a una serie de "encabezamientos" que conciernen a la finalidad (telos) a los actos, lo que, en principio, permiten evaluar si una acción propuesta está bien fundada o no."

Recordemos, antes de mais, os quatro núcleos argumentativos: o orador há de demonstrar que a ação que pretende levar a cabo é justa (iustum), útil (utile) uma vez que satisfaz uns interesses e evita consequências nefastas, é possível (possibile) de ser realizada, além de ser honrosa (dignum). A estes quatro, pode ainda acrescentar-se um tópico muito frequente na historiografia greco-latina, que adverte para as terríveis consequências da derrota (ekbesomenon). Comecemos então pela linha didático-instrutiva.

\section{a. Linha didático-instrutiva (didache)}

A designação de linha didático-instrutiva deriva do facto de nela o capitão expor o plano estratégico-tático a executar na batalha que se há de seguir. É certo que ao receber o plano estratégico do combate, a assembleia de capitães e/ou de soldados recebe já uma mensagem clara de motivação, contudo, se atendermos ao termo original com que Tucídides denominou esta parte da arenga, didache, divisaremos que nela estão implicadas as ideias de "instruir" e de "recordar". Significa então que o chefe militar há de, não só instruir taticamente as suas tropas para a batalha, como deverá enaltecer os motivos favorecedores de ânimo, a fim de inspirar nos homens a confiança necessária para enfrentarem o inimigo

\section{a.1. A conveniência e a necessidade da luta (utile et necessarium)}

Encarecer a conveniência, a necessidade, ou se quisermos a utilidade da luta, é um dos tópicos fundamentais da argumentação instrutiva das arengas historiográficas portuguesas de Quinhentos.

Sempre que os chefes militares anunciam aos seus subalternos a decisão de efetuar a conquista ou a defesa de uma posição estratégica para o Estado português, tratam de enumerar todos os potenciais benefícios que derivam dessa iniciativa tanto para o Estado, como pelo serviço que fazem a Cristo,

9 Iglesias Zoido 2008:8.

Humanitas 66 (2014) 349-365 
como ainda, para cada um dos intervenientes na dita empresa. Dito de outro modo, este é um lugar-comum que apresenta larga expressão nas arengas T1.

De entre as diferentes arengas que atestam a tese acima enunciada, selecionámos a arenga (T1) do governador da Índia, Afonso de Albuquerque, quando, subitamente viu a capital do Estado da Índia, Goa, cercada por 10.000 mouros e turcos. Chamando os principais da sua armada, mostrou-lhes a importância que a cidade de Goa assumia tanto para os interesses portugueses na região como para a Cristandade, encarecendo-lhes, de todas as maneiras, a conveniência de susterem aquele assédio, até que chegassem homens frescos de Portugal. A arenga assenta na amplificação do tópico do conveniente. Afonso de Albuquerque enumera, com precisão, as conveniências de que a capital, Goa, permaneça, a todo o custo, portuguesa:

[Nosso Senhor] nos ajudará, para que defendamos esta cidade, que he a principal cousa da Índia, assi em fortaleza como em riqueza, e em que os mouros tem mais sua esperança; e por isso cõstituyão nela como vistes contra nos a cabeça da guerra. E se a sostemos a este ímpeto presente, credeme que não teremos mais necessidade de pelejar na Índia, e que todos os reys dela hão de ter nossa amizade em muyta estima, e averse por muyto ditosos de ter paz cõnosco, e cõfirmarão por verdadeira a opinião que tem de nos de sermos mais valentes que os rumes (...). ${ }^{10}$

Segundo Albuquerque, mantendo-se Goa portuguesa, não haveria necessidade de mais pelejar na Índia, porquanto imediatamente todos os reis acorreriam a pedir acordos de paz com os Portugueses, de tal maneira que o respeito pelos lusos desalojaria o que dantes existia com os rumes.

Depois de apontarem as vantagens da luta para o Estado, por vezes, os oradores, para envolveram mais as tropas na batalha, descem aos seus interesses afetivos mais próximos, o património e a família. Trata-se de um tópico com enorme fortuna retórico-historiográfica, presente logo na Íliada, onde ganha uma enorme preponderância, pois lutar por ambos fazia parte do código de honra do herói homérico. Variados são os exemplos, trazemos aqui, apenas, a arenga de Nestor em forma de súplica:

(...) lembrai-vos, cada um de vós, dos vossos filhos e mulheres, dos haveres e dos pais, independentemente de serem vivos, ou já mortos.

10 Castanheda, História, 3.20. 
Por aqueles que aqui não estão vos suplico que firmes permaneçais e que não vireis as costas em fuga. ${ }^{11}$

Agora, atente-se na similitude desta com a arenga (T2) de António da Silveira aos soldados portugueses, quando os turcos se preparavam para o último assalto a Diu. Embora, no opúsculo de Damião de Góis, o discurso surja breve e em estilo indireto, é fácil comprovar a cristalização deste tópico:

Qua re perculsus Antonius a Silveira, milites omnes ilico convocat, quibus fidem, nativum solum, Regem, uxores, filios, parentes, amicos (...). ${ }^{12}$ Consternado por isso, António da Silveira convoca imediatamente todos os soldados, aos quais relembra fé, o solo pátrio, o Rei, as esposas, filhos, parentes, amigos (...).

Para encerrarmos este tópico do "conveniente" ou do "necessário", cumpre ainda olhar para uma variante. Trata-se de mostrar aos combatentes que a batalha que se avizinha é decisiva e cuja importância se sintetiza numa lapidária como "vencer ou morrer", não existe mais nenhuma via. Este é um tópico parenético e caraterístico do comportamento heróico, surgindo por exemplo várias vezes na Ilíada de Homero e um pouco em toda a historiografia antiga, tendo ficado conhecido pela expressão de Tito Lívio (21.5) uicendum aut moriendum. Esta necessidade extrema de lutar para salvar a vida é também definida por Lívio como o ultimum et maximum telum, referindo-se ao capitão dos volscos, que, vendo-se subitamente cercado por dois exércitos romanos, entendeu que os seus homens ou abriam caminho à espada ou morriam, pronunciando a seguinte arenga (4.28):

Ite mecum; non murus nec vallum, armati armatis obstant; virtute pares, quae ultimum ac maximum telum est, necessitate superiores estis / Segui-me! Não é um muro ou uma vala, mas homens armados que se opõem a outros homens armados: e se a virtude se equipara em ambos os exércitos, tendes a vantagem da necessidade que vos constrange, que é a arma extrema e máxima.

Vamos encontrar este tópico na arenga (T2) de D. Sebastião, em Alcácer Quibir:

11 Hom. Il. 15.662-6.

12 Góis, Diensis, 69. 
Deos me quer dar a victoria, pois me offereceo esta batalha em tal sitio, onde o rio, que nos fica nas costas, e o imigo que temos no rosto, nos ameaçaõ total perdiçaõ, se tornarmos atráz, e nos obrigaõ hir adiante, pondo toda a esperança da nossa saúde na victoria, e sei mui bem, entre muitos indícios, que tem pera hoje serem desbaratados, estaõ mui temerosos de nossa determinaçaõ, e por estarmos em parte e em lugar, onde, como gente desesperada de poder escapar com fugida, naõ temos outro remedio senã̃ desbarata-los, pera segurarmos nossas vidas, e ganharmos suas terras. ${ }^{13}$

Como declara o rei, as condições físicas do local em que se desenvolve a batalha só admitem a vitória para que os Portugueses saiam dali com vida: atrás têm um rio que impede a fuga e à frente têm um exército, logo só a vitória garante a salvação. Infelizmente, de vencer ou morrer, foi a segunda alternativa que imperou.

\section{a.2. Justiça da luta (Iustum)}

Este é o topos mais frequente e por consequência mais importante das arengas quinhentistas. Defender numa arenga a "justiça" da luta tem forçosamente como contrapartida que Deus ou os deuses se posicionem ao lado da hoste que é exortada. Neste sentido, os capitães procuram demonstrar, por diferentes vias, que os combatentes que os escutam defendem uma causa justa, granjeando, automaticamente, o apoio divino. Assim, quando D. João de Mascarenhas diz aos capitães de Diu (T1): Alembrevos que temos IESU CHRISTO /Por nosso capitam: e que está certo / Vencermos, pelejando contra imigos / De sua Fé sagrada, ${ }^{14}$ está a motivá-los para a guerra, invocando a proteção divina, recordando-lhes que, ao lutarem contra os inimigos da Fé, atraem sobre si o favor de Cristo, estando, portanto, garantidos os inerentes galardões da bem-aventurança eterna.

No processo expansionista que levou à constituição do imperium português, os defensores e promotores do mesmo procuraram fundamentá-lo, sempre que necessário, à luz do conceito legal da guerra justa. Conceito e ordenamento jurídico que contava já com larga tradição histórico-jurídica que os Portugueses de então interpretaram e adaptaram à sua realidade e cujas obras históricas e as arengas nelas inseridas serviram como órgão difusor.

13 Vaena, Crónica de El Rei D. Sebastião, 54.

14 Corte Real, Sucesso, 4. 
No poema épico de Jerónimo Corte Real, o capitão da fortaleza de Diu em 1546, D. João de Mascarenhas exorta os seus capitães à luta, declarando que aquela guerra contra os cambaicos era justa:

Esforçados senhores, valorosos,

Usados a trabalhos, e a perigos,

Bem vedes este cerco tam soberbo,

Que Mamude nos poem sem causa justa. ${ }^{15}$

Uma pouco mais adiante, Mascarenhas entra, pois, analiticamente, na exposição das ilegalidades cometidas por aqueles sitiantes. Quebraram todos os acordos de paz firmada, são gente sem palavra e só os move a perfídia, nem na vitória mostram qualquer ato de clemência. Portanto, esta guerra é, a todos os títulos, justa de se empreender:

Lembrovos que este imigo he fraudulento,

Quebrantador do pacto, e a paz firmada,

Que nam guarda palavra prometida,

Nam saberá vencer, nem cós vencidos

Terá clemencia algũa; atentay todos

Que esta guerra he muy justa, pois quebraram

Contratos, condições entre nós postas.

Como se vê, a justa causa da guerra podia também ser invocada para denunciar o incumprimento de leis ou de acordos estabelecidos, aplicando-se também como forma de retaliação contra qualquer tipo de injúria ou agressão, efetuado contra a pátria, contra o património ou mesmo contra a família.

Se no plano diplomático, se procurava defender o interesse nacional, apresentando-o como um serviço prestado ao bem comum da Respublica Christiana, no plano historiográfico, os historiadores, lançando mãos daquelas breves frases proferidas pelos capitães, amplificavam-nas e compunham um discurso de acordo com as normas retóricas vigentes. Só que, agora, os recetores dessas arengas já não eram os soldados, mas sim os muitos leitores das obras históricas, portugueses, mas também estrangeiros. Neste sentido, as arengas historiográficas tornaram-se num instrumento privilegiado para convencer os leitores sobre a justiça e

15 Corte Real, Sucesso, 4.

Humanitas 66 (2014) 349-365 
santidade da empresa comercial e espiritual portuguesa, desempenhando assim um notável papel propagandístico.

\section{b. Linha exortativa (Parakeleusis)}

Entramos agora na linha exortativa presente no final de algumas arengas mais extensas (T1, T2, T3), além de coincidir com a única linha argumentativa da generalidade dos discursos T4 e T5. A designação desta componente discursiva advém justamente do facto de nela o orador galvanizar emotivamente os soldados para a iminência da batalha (mouere), levando-os a emular os antigos e a preferir uma "bela morte" à desonra.

Não podemos inferir que, pela sua limitada extensão, o correspondente conteúdo argumentativo seja também menos relevante. Ao contrário disso, estas últimas palavras eram aquelas que ficariam registadas na memória dos combatentes e que, possivelmente, ainda ecoariam no momento da refrega. Certamente que os oradores e os cronistas não deixariam de ter isso em conta, adaptando esta parte do discurso às exigências temporais e circunstancias de enunciação.

Esta componente do discurso tem, geralmente, a apartá-la da anterior, uma conjunção ou locução conclusiva, seguida de frases marcadas por imperativos e por conjuntivos exortativos, assim como por sentenças, de acordo com o ato ilocutório diretivo ali presente.

Por tudo isto, não surpreende que o topos retórico mais frequente na linha exortativa seja aquele que se reporta aos motivos éticos (honestum et dignum). Aí temos Duarte Pacheco exortando os seus homens (T2) a combaterem o rei Calecut, cuja vitória trará honra entre os Portugueses e fama entre estrangeiros:

(...) por tanto lembrevos que coesta confiãça aveis de pelejar pera vos nosso senhor fazer tamanha merce como sera darvos vitoria cõ honrra sobre todos os Portugueses, e fama antre estrãjeiros, e merecimẽto diãte del rey nosso senhor pera vos fazer merces cõ que sustenteis vossas vidas. ${ }^{16}$

Significativas são as palavras de D. João de Castro, durante os combatentes ao redor de Diu. Elas atestam que a honra se sobrepunha, retoricamente, a todo o tipo de riquezas materiais (T5):

16 Castanheda, História, 1.68. 
(...) dizendo aos soldados que soubessem seguir a vitória que Deus lhes dava, a qual havia de ser a mor que nunca se no mundo visse, e que só para eles fora guardada aquela honra, que eles haviam de estimar por cima de todas as riquezas da vida. ${ }^{17}$

\section{Conclusões}

Pelo exposto, se começa a compreender o verdadeiro significado da assídua presença da arenga militar na historiografia. É certo que a arenga militar, como qualquer outro tipo de discurso, é um poderoso instrumento de construção dos careteres das personagens (etopeia). É igualmente um recurso utilizado pelos historiadores para explicar e antecipar as ações bélicas que a seguir se hão de seguir, uma vez que nas arengas prévias, o orador tem por hábito apresentar às tropas o desenho estratégico que se porá em prática. Do mesmo modo, a partir desse desenho tático, o leitor pode inferir os reais motivos que estiveram por detrás de uma vitória e mesmo de uma derrota. Por outro lado, a inserção da arenga militar nas narrativas pode revelar-se como meio para os autores exercitarem o seu domínio nas técnicas retórico-estilísticas de composição do discurso. Todas estas funções são desempenhadas pelas arengas militares no contexto geral das obras históricas em que estão inseridas.

A arenga militar historiográfica foi também um instrumento privilegiado de propaganda da ideologia oficial orientada para a cruzada contra o Infiel e a consequente defesa dos interesses ultramarinos. O leitor europeu ficaria certamente consciencializado de que a luta dos Portugueses era legítima (bellum iustum), pois, de todos os povos cristãos que então se entretinham em dirimir questiúnculas, os Portugueses eram os únicos que se empenhavam em manter afastada da Respublica a ameaça turca.

\section{Bibliografia ativa}

Castanheda, F. (1979), História do Descobrimento e Conquista da Índia pelos Portugueses. 2 vols., Porto: Lello \& Irmão Editores.

Castro, F. (1995), Crónica do Vice-Rei D. João de Castro. transc., e notas. de Luís de Albuquerque e Teresa Travassos Cortez da Cunha Matos, Tomar: Escola Superior de Tecnologia de Tomar.

17 Fernando de Castro, Crónica, 46, (II Parte).

Humanitas 66 (2014) 349-365 
Corte Real. J. (1979), Obras de Jerónimo Corte Real, Sucesso do Segundo Cerco de Diu, Naufrágio de Sepúlveda, Auto dos Quatro Novíssimos do Homem, Elegias. int. de M. Lopes de Almeida, Porto: Lello \& Irmão Editores.

Couto, D. (1777-1788), Da Ásia de João de Barros e de Diogo do Couto: dos Feitos Que os Portugueses Fizeram no Descobrimento e Conquista dos Mares e Terras do Orient., Décadas V, VI, VII, IX, X, XI, XII. No sítio da Biblioteca Nacional Digital, consultado em http://purl.pt/7030 (30/08/2013).

Góis, D. (1544), Diensis Nobilissimae Carmaniae seu Cambaiae vrbis oppvgnatio, Damiano a Goes autore, in Damiani a Goes Equitis Lusitani Aliquot Opuscula, Louanii, ex Officina Rutgeri Rescii, anno 1544, mense Ianuario. in Obras de Damião de Góis (2002), Vol. II (1539-1540), trad. Miguel Pinto de Meneses, int. e notas de Manuel Cadafaz de Matos, Lisboa: Edições Távola Redonda.

Homero (2010, $4^{\mathrm{a}}$ ed.), Ilíada. trad. de Frederico Lourenço, Lisboa: Livros Cotovia.

Tucídides (2008), História da Guerra do Peloponeso. trad., estudo militar introdutório e notas de David Martelo, Colecção Clássicos do Pensamento Estratégico, Lisboa: Edições Silabo.

Vaena, A. (1903), Chronica d'el-rei D. Sebastião. Lisboa: Escriptorio.

\section{Bibliografia passiva}

Bliese, J. (1989), "Rethoric and Morale: A Study of Battle Orations from the Central Middle Ages", Journal of Medieval History 15, 201-226.

(1991), "When Knightly Courage May Fail: Battle Orations in Medieval Military Manuals", Rhetorical Society Quarterly 24, 105-130.

(1994), "Rhetoric Goes to War: The Doctrine of Ancient and Medieval Military Manuals", Rhetoric Society Quarterly 25.3, 105-130.

Chaparro Gómez, C. (2008), "La Arenga Militar en la Edad Media: Estudio de algunas crónicas hispanas", in J. C. Iglesias Zoido (ed.), Retórica e Historiografia: el discurso militar desde la Antigüedad hasta el Renacimiento. Madrid: Ediciones Clásicas, 405-428.

García Fitz, F. (2008), "La Arenga Militar en la Historiografía de las Cruzadas: la Ideología Patente", in J. C. Iglesias Zoido (ed.), Retórica e Historiografia: el discurso militar desde la Antigüedad hasta el Renacimiento. Madrid: Ediciones Clásicas, 429-466.

Hansen, M. H. (1993), “The Battle Exhortation in Ancient Historiography. Fact or Fiction?", Historia 42, 161-180.

Harto Trujillo, M. (2008), Las arengas militares en la historiografia latina, Madrid: Ediciones Clásicas 
Iglesias Zoido, J.C. (2008), "Retórica e Historiografía: La Arenga Militar", in J. C. Iglesias Zoido (ed.), Retórica e Historiografia: el discurso militar desde la Antigüedad hasta el Renacimiento. Madrid: Ediciones Clásicas, 19-60. (2008a), "La arenga militar en la Historiografía griega: el modelo de Tucídides y sus antecedentes literarios y retóricos", in J. C. Iglesias Zoido (ed.), Retórica e Historiografia: el discurso militar desde la Antigüedad hasta el Renacimiento. Madrid: Ediciones Clásicas, 231-258.

Henriques, L. (2013), La arenga militar en la historiografía, en la épica y en los tratados militares en lengua portuguesa y en lengua latina del siglo XVI. Tese de doutoramento apresentada à Facultad de Filosofía y Letras da Universidad de Extremadura: Cáceres.

Navarro Antolín, F. (2000), "La Retórica del discurso: la Cohortatio, Tradición clásica y pervivencia”, Cuadernos Filologia Clásica 19, 79-124. 